\title{
Social-and-Ecological Metabolism of the Russian Megalopolis under the Influence of Sports Megaevents
}

\section{*Polina Ermolaeva}

*Kazan Federal University, Institute of Social and Philosophical Studies and Mass Communication; Center of Advanced Economic Research of the Academy of Sciences of the Republic of Tatarstan.

Email: polina.ermolaeva@ gmail.com

\author{
Received: 15th December 2017, Accepted: 20th December 2017, Published: 31st December 2017
}

\begin{abstract}
In article on materials of a complex empirical research of the large Russian city on the example of Kazan, its social-and-ecological metabolism with emphasis on mutual changes of natural, social and technical processes under the influence of sports megaevents is studied (A Universiade of 2013, the water sports World Cup - 2015). Complex studying of processes of social-and-ecological metabolism of Kazan became research result, including practice of ecological cooperation and resistance. Each of processes is connected with each other. Complexity of processes such is that ecopractice of cooperation (on the intension) de facto can generate harmful metabolic chains, thereby creating "Butterfly Effect".
\end{abstract}

Keywords: Social-and-Ecological Metabolism, Megalopolis, Metabolic Processes, Sports Megaevents, Urban Environment, Ecological Practicians, Ecological Conflicts

\section{Introduction}

Today in Russia there take place a set of sports megaevents: in July, 2013 in Kazan played the World student's games (Universiade), in February, 2014 Sochi hosted the Winter Olympic Games, in 2015 in Kazan there took place the water sports World Cup, in 2017 the World Sambo Championship will be held, in 2018 ten Russian cities will host the FIFA World Cups.

Preparation and holding sports megaevents made a set of changes to city space, including change of infrastructure, daily occurrence of citizens, business and civil activity, an ecological situation, a services sector and tourism. Changes in one spheres generated changes in others, became irreversible and invisible to the cities and the population.

We will study these interactions and mutual transformations of natural, social and technical environments and processes in categories of socialand-ecological metabolism [1,2,3,4,5]. In Englishspeaking literature often, the concept of city metabolism is symmetric with metabolism of organisms, considering the cities as an ecosystem. The cities it is similar to natural organisms - consume resources and allocate waste. "The cities transform raw materials, fuel, and water on artificial environment, biomass and waste" [6]. Of course, the cities are more difficult, than natural organisms [3].

The analysis of social-and-ecological metabolism of Kazan with emphasis on mutual changes of natural, social and technical processes under the influence of sports megaevents (A Universiade of 2013, the water sports World Cup - 2015) became an objective of this research.

Kazan as a research case was chosen by us not incidentally as one of the first Post-Soviet cities owners of a megaevent the "Universiade-2013 of" which became "rehearsal" of the Olympic Games in Sochi in 2014 and also carrying out in 2015 the water sports World Cup and in 2018 the FIFA World Cup.

\section{Research Methodology}

Within a case-study which acted as methodological base of a research we chose a combination qualitative and quantitative research strategy with use of the following methods of collecting sociological informatsii:1) the analysis of documents (polls, a discourse analysis of media, federal and regional programs etc.) was to conduct at the initial stages researches for studying of the existing discourse in the field of the city changes connected with holding megaevents, regional features and also definition of a pool of experts for holding an interview. 2) A method of the semi-structured expert interviews $(n=15)$. We conducted interviews with the faculty, research associates of the research and town-planning organizations, leaders of ecological and citizens' initiatives of Kazan, representatives of Organizing Committee of Games. The research was conducted in May, 2016 3) the Method of mass poll (the multistage stratified selection ( $n=500$ of people). The research was conducted by group of scientists within a grant of RGNF "Social Consequences of Preparation and Holding the International Sports Megaevents for Local Communities in the Cities of Post-Soviet Russia (on the example of the Universiade in Kazan-2013 and Olympic Games in Sochi-2014 of)" in 2013. Data of 
mass poll allowed us to obtain the interviewed information on changes in the urban environment reflected in consciousness, directly after holding megaevents.

\section{Findings}

The ecological actions which influenced change of SEM of Kazan can be carried to those which caused improvement of the environment and to those which led to the ecological conflicts, ecological disruption of the city. In other words, in O. N. Yanitsky's categories they will be divided on "useful" and "harmful" [7]. And in most cases those actions which were considerably spread around by political elite in media as ecologically significant brought finally minor temporary changes in city SEM whereas the ecological conflicts or considerable narrowing of natural space (parks, green zones) for the account emergence of new shopping centers, parking had for city SEM, in particular for health and activity of the population, more essential and irreversible effect. We suggest considering each of these "knots" separately.

The Green Landing program was specially organized just before holding the Universiade - a series of the actions directed to planting of trees, and also the organization of community work days and the general upclassing of image of the city. In total gardening within "A green record" captured 2656 platforms on all city, 638 sections of streets and 1615 house adjoining territories - practically every third yard in the city. The population assessed this initiative positively: the city became purer $(47,8 \%)$, more "green" (30,4\%) [8]. However, experts stated more reserved estimates to this initiative: the opinion was expressed that gardening happened only in public places: suburbs of the city and "sleeping" areas were not captured by an action, were absent the supporting actions: "... Personally at me in the yard according to this program 2 or 3 trees and these trees after literally half a year were planted they disappeared, did not get accustomed" (the representative of the academic sector).

To similar in fact actions, specially organized to Games, temporary emergence of containers for sorting of garbage was referred. The pilot program for sorting of household waste became one of platforms on formation of the "supporting" infrastructure. In the city 47 containers intended for sorting of glass, plastic and paper were put. Repeatedly representatives of the Ministry of Ecology and Natural Resources of the republic conducted public raids to learn reaction of citizens of Kazan to new containers, to collect opinions on improvement of their design and need for different districts of the city. "These containers - the single phenomenon, but almost in each yard appeared containers for collecting plastic bottles" (the representative of the town-planning sector).

On the other hand, containers were put, but the broad information campaign for sorting of household waste was not conducted - according to poll of $11,4 \%$ of the population noted that they do not know how to use these containers. It led to the fact that containers were used incorrectly that led to the whole chain of reactions and metabolic changes to the external environment (pollution of soils, sewage etc.), was not constructed the most important component of a chain - waste recycling plant.

Besides the practician of city cooperation it is possible to observe practicians of resistance ("harmful" metabolic transformations) organized by groups of citizens' initiatives concerning construction of KazanArena stadium on the right river bank Cauldrons, a case of the Rowing channel and depriving of property, the private ecological conflicts - the organization of citizens' initiatives against cutting down of trees in Privolzhsky district of Kazan under construction of the road to the Village of the Universiade, shooting of stray dogs, etc. [8]. The specified ecological conflicts and protests, concern of the population in lack of public hearings around construction of facilities of the Universiade made revolutionary changes in city SEM, became the most risk points for city space.

The similar conflicts generated a set of direct and indirect processes which were reflected in an ecological and social landscape of the city, had irreversible consequences for SEM of Kazan. Among consequences for SEM of the city it is possible to note: ecological consequences (destruction of a biodiversity, deterioration of drinking water, the "missed" ecological and recreational opportunities).

Besides negative consequences for ecology, construction of facilities of the Universiade had positive effect for city space - considerably diversified an esthetic landscape of the city that favorably affected all-psychological perception of the urban environment: "From a position of video of ecology, I consider Universiade constructions very much diversified the general image of the city. The matter is that monotonous multystoried building and it is already proved by numerous researches, it leads to deterioration in psychological state of citizens, i.e. these big quarters which are created according to the program of a social mortgage, from the point of view of visualization are extremely adverse" (the representative of public sector). 


\section{Conclusion}

Such example in the former Soviet Union became Kazan which for rather small period of time underwent a number of metabolic mutual changes which we conceptualized in groups the practician of ecological cooperation and ecological resistance.

We carried to the main social-and-ecological consequences of "knots of city ecological cooperation": improvement in an ecological and social situation of the city (improvement of quality of air and a noise isolation, dust removal, improvement of esthetic perception of the city, increase in appeal of the city, patriotism growth, improvement of the general health of citizens, etc.) due to creation of the temporary "the supporting infrastructure", joint civil ecoaction due to involvement of different segments of the population in ecopractice, ecotraining through activity, etc.

We carried to the main social-and-ecological consequences of "knots of city ecological resistance": ecological consequences (destruction of a biodiversity, deterioration of drinking water, the "missed" ecological and recreational opportunities, a variety of an esthetic landscape of the city due to construction of new sporting venues that affects all-psychological perception of the urban environment), social consequences (strengthening of citizens' city initiatives, a communication resonance, apathy among the population and growth of paternalism as result of a victory of political elite in the town-planning conflicts, naturalization of permissiveness of anti-ecological decisions of the authorities, polarization among professional ecologists, etc.)

Each of these "knots" generates a set of visible and invisible interdependent metabolic transformations which we divided on useful and harmful. Each of processes is connected with each other. And complexity of processes such is that ecopractice of cooperation (on the intension) de facto can generate harmful metabolic chains, thereby creating "Butterfly Effect". For example, lack of knowledge and training of the population in practicians of sorting of garbage at the created supporting infrastructure (installation of tanks for sorting of garbage) led to the wrong sorting of garbage that negatively influenced other ecological processes - pollution of soils, water objects that in turn affected on health and wellbeing of citizens. In turn ecopracticians of city resistance provoked strengthening of city initiatives that generated a number of useful metabolic chains - ecotraining through activity, increase in ecoculture and activity of citizens, improvement of the environment, health and health of the population, etc.

\section{Discussion}

The pragmatical sense of sports megaevents as powerful engines of metabolic transformations in the cities consists in need of "swift development of federal funds" in a short time. Similar conditions "put the local organizations in a difficult situation - it is necessary to master the allocated funds by all means by certain time ... therefore make quick decisions" (the representative of the academic sector). It generates illusion of "jump" of ecological concern of the authorities during megaevents that is perceived rather as the necessity caused by economic incentives (growth of tourist flow, etc.), but not as validly by care of the environment and health of citizens, etc. It certainly affects metabolic processes in the city, many of which proceed in the abnormal mode in the course of preparation for Games. The saddest that the unreasoned and hasty urban policy can lead to losses not only for a social-and-ecological framework of the city, but also it is unprofitable eventually for the authorities.

\section{Acknowledgements}

The work is performed according to the Russian Government Program of Competitive Growth of Kazan Federal University.

Work is prepared within the research project "Complex Research and Creation of Crossdisciplinary Model of Social-and-ecological Metabolism of the Modern Russian City" which is carried out with assistance of the Russian Federal Property Fund, a grant No. 15-06-00158a

\section{References}

1.Yanitsky O.N. Metabolism as a master frame for globalization analysis. 2017. URL: <http://www.isras.ru/publ.html? id=4930>

2.Yanitsky O. N. Socio-bio-tech of system: a new view on interaction of the person and the nature//Social science and social practice, 3(15) 2016

3.Ermolaeva P. Citizen (Dis)engagement during Assessment of Sports Mega-events: Case of the 2013 Universiade in Kazan, Russia//Impact Assessment and Project Appraisal. 2014. Vol. 32. Issue 1. - Pp. 66-71.

4.Fischer-Kowalski M and Weisz H (1999) Society as hybrid between material and symbolic realms: Toward a theoretical framework of society-nature interaction. Advances in Human Ecology 8: 215-251.

5.Broto VC, Allen A and Rapoport E (2012) Interdisciplinary perspectives on urban metabolism. Journal of Industrial Ecology 16(6): 851-861. 
6.Gandy M. Rethinking urban metabolism: water, space and the modern city: City: analysis of urban trends, culture, theory, policy, action, 8:3, 363-379, 2004.

7.Yanitsky O. N. Socio-bio-tech of system: a new view on interaction of the person and the
nature//Sociological science and social practice, 2016, No. 3, page 5-22.

8.Yermolaeva P. O. 2014. New tendencies in ecological consumption of Russians under the influence of sports megaevents (on the example of the Universiade of 2013, Kazan)//the Labyrinth. Magazine of social and humanitarian researches, 2, 52-63 